\title{
Azygoesophageal fistula: a rare cause of upper gastrointestinal tract bleeding
}

A 73-year-old man, who had a history of thoracic aorta aneurysm and aortic valve replacement operations 25 years ago and anemia diagnosed 4 years previously who was currently taking warfarin, propranolol, and iron preparations, presented to the emergency department with melena and hematemesis. His blood pres-

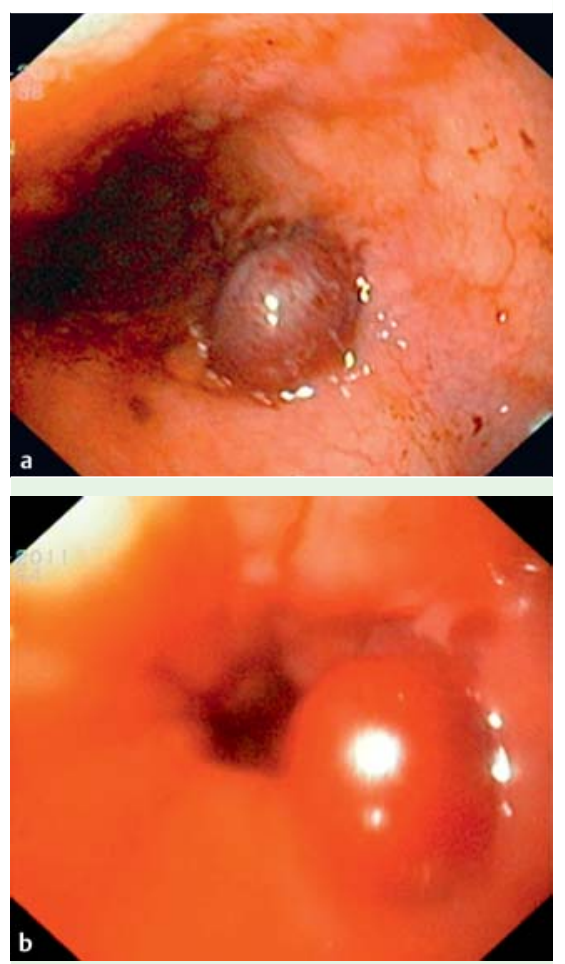

Fig. 1 Endoscopic appearance in a 73-year-old man with a history of thoracic aorta aneurysm surgery and aortic valve replacement who presented with melena and hematemesis showing the azygos vein protruding into the esophageal lumen $7-8 \mathrm{~cm}$ proximal to the cardioesophageal junction. sure was $90 / 60 \mathrm{mmHg}$ and his heart rate was 108 beats per minute. Investigations showed he had hemoglobin $(\mathrm{Hb})$ of $9 \mathrm{~g} / \mathrm{dL}$ and an international normalized ratio (INR) of 2.3.

He underwent an upper gastrointestinal endoscopy, which revealed a lesion protruding to the lumen that was $8-10 \mathrm{~mm}$ in size and magenta-colored, consistent with a vascular structure $7-8 \mathrm{~cm}$ proximal to the cardioesophageal junction

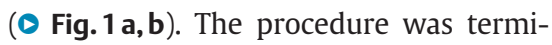
nated without an endoscopic therapeutic intervention and the patient was admitted to the intensive care unit.

He underwent a computed tomography angiogram (CTA) 7 hours later in the interventional radiology unit, which showed postoperative changes in the ascending aorta, prominent azygos and hemiazygos veins, widespread intra-abdominal retroperitoneal venous collaterals, and web formation at the location of the opening of the inferior vena cava to the right atrium ( Fig.2). Percutaneous thoracic angiography (PTA) showed a marked degree of stenosis between the vena cava and the right atrium. This was treated by balloon dilation using angioplasty balloons with diameters of $10-25 \mathrm{~mm}$ during the same session, with improvement in the appearance of the stenotic segment and in the pressure gradient ( $\bullet$ Fig.3). No problems were encountered during the follow-up period and the patient remains under ongoing follow-up in our outpatient clinic.

Azygoesophageal fistula is a rare cause of upper gastrointestinal tract bleeding. Shieh et al. reported a case in which bleeding from an azygoesophageal fistula was defined and safely occluded by sclerotherapy with Lipiodol [1]. Our report shows that endovascular treatment is a safe and effective treatment option for azygoesophageal fistulas.

Endoscopy_UCTN_Code_CCL_1AB_2AC_3AG

\section{Competing interests: None}

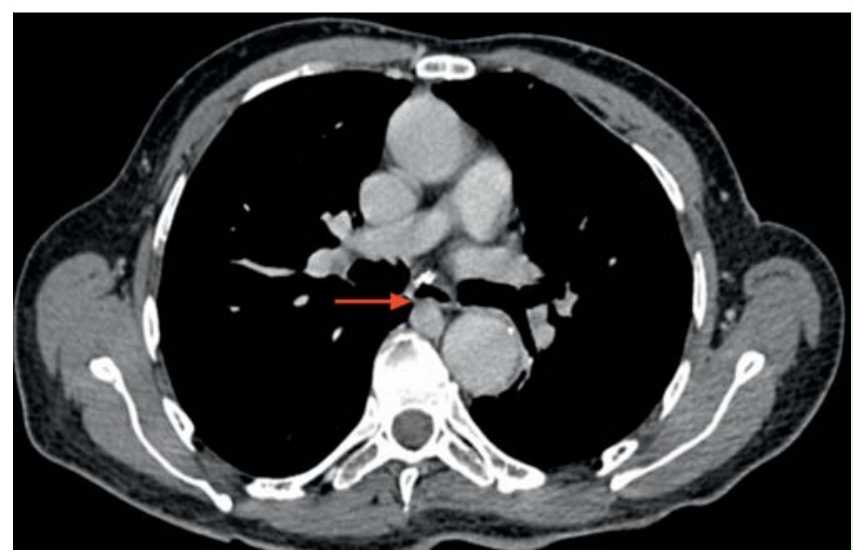

Fig. 2 Image taken during the venous phase of computed tomography angiography (CTA) showing dilatation of the azygos vein, which was protruding through the posterior wall of the esophagus into the esophageal lumen (red arrow). 


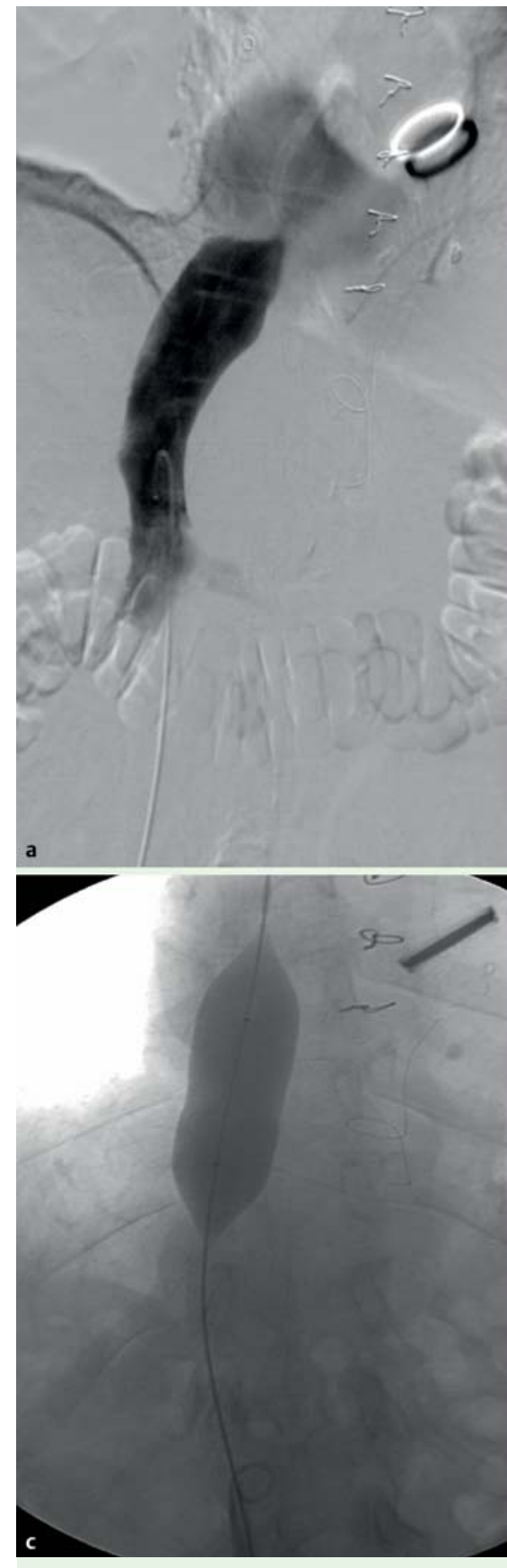

Fig.3 Images taken during percutaneous thoracic angiography (PTA) showing: a a marked degree of stenosis related to the web seen at the atriocaval junction during imaging of the inferior vena cava; $\mathbf{b}$ reflux of contrast into the hemiazy-

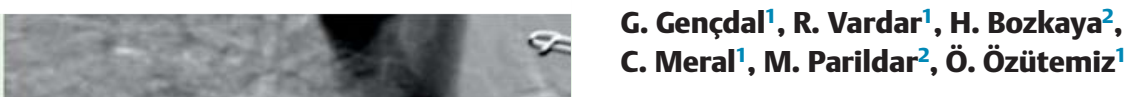

${ }^{1}$ Department of Gastroenterology,

Ege University School of Medicine, İzmir, Turkey

${ }^{2}$ Department of Radiology, Ege University School of Medicine, İzmir, Turkey

\section{References}

1 Shieh TY, Lin CC, Yang FS et al. Azygoesophageal fistula successfully treated with endoscopic injection of N-butyl-2-cyanoacrylate. Endoscopy 2011; 43: E168-E169

\section{Bibliography}

Dol http://dx.doi.org/

10.1055/s-0032-1326281

Endoscopy 2013; 45: E219-E220

(c) Georg Thieme Verlag KG

Stuttgart · New York

ISSN 0013-726X

\section{Corresponding author}

\section{G. Gençdal, MD}

Ege üniversitesi tıp fakültesi hastanesi

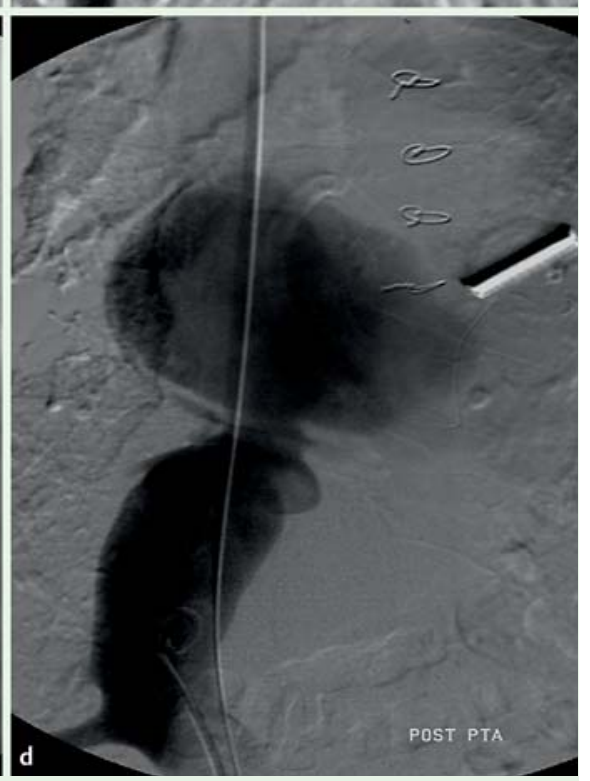

gastronenteroloji

Kliniği bornova

İzmir 35040

Turkey

Fax: +90-232-3427764

genco.gencdal@ege.edu.tr gos-azygos venous system during the late phase atriocaval web being performed with an angioplasty balloon; $\mathbf{d}$ improvement in the stenotic segment following the PTA procedure. 